И.Л.Горелик ${ }^{1}$, Е.Н.Калманова ${ }^{1}$, З.Р.Айсанов ${ }^{2}$, А.Г.Чучалин ${ }^{2}$

\title{
Функционально-структурные изменения сердца при хронической обструктивной болезни легких в сочетании с ишемической болезнью сердца
}

1 - Городская клиническая больница № 57: 105077, Москва, ул. 11-я Парковая, 32;

2 - ФГУ "НИИ пульмонологии ФМБА России": 105077, Москва, ул. 11-я Парковая, 32, к. 4

\author{
I.L.Gorelik, E.N.Kalmanova, Z.R.Aisanov, A.G.Chuchalin
}

\section{Functional and structural disorders in patients with co-existing chronic obstructive lung disease and ischaemic heart disease}

\begin{abstract}
Summary
The present study was aimed at evaluation of functional and structural disorders in patients with co-existing chronic obstructive pulmonary disease (COPD) and ischaemic heart disease (IHD). Methods of conventional and tissue Doppler echocardiography were used. The study involved 144 patients divided into 3 groups: 59 patients with stage I-III COPD (the $1^{\text {st }}$ group), 56 patients with co-existing COPD and IHD (the $2^{\text {nd }}$ group), and 29 smokers without clinical and functional signs of cardiac and respiratory pathology as controls (the $3^{\text {rd }}$ group). All the patients were examined using lung function tests and echocardiography. Planimetric and haemodynamic parameters of tissue Doppler echocardiography were compared between groups. The left atrium volume index differed between all the groups: $29.2 \pm 3.5$ in the $1^{\text {st }}$ group, $33.7 \pm 2.95$ in the $2^{\text {nd }}$ group and $24.1 \pm 2.3$ in the $3^{\text {rd }}$ group. The most remarkable difference between the groups was seen for E / Em ratio of the left ventricle: this value increased by $49.1 \%$ in the $1^{\text {st }}$ group and by $132.7 \%$ in the $2^{\text {nd }}$ group compared to controls. Left ventricular diastolic dysfunction (LVDD) was revealed in $57.6 \%$ of the $1^{\text {st }}$ group patients and $98.2 \%$ of the $2^{\text {nd }}$ group patients. Systolic pulmonary artery pressure was $15 \%$ higher in the $1^{\text {st }}$ group patients and $55 \%$ higher in the $2^{\text {nd }}$ group when compared to controls. Significant pulmonary arterial hypertension in the $2^{\text {nd }}$ group patients affected right ventricular function: the myocardial performance index (MPI) of the right ventricle was twice higher in COPD patients and even more in patients with combined pathology. The $1^{\text {st }}$ group and especially the $2^{\text {nd }}$ group patients showed decreased ratio of early and late diastolic waves in the tissue Doppler image in the lateral tricuspid annulus; this fact confirms worsening of LVDD in patients with combined pathology vs COPD patients. Therefore, tissue Doppler echocardiography could be useful to detect early stage diastolic dysfunction of both the ventricles which could not be found with the impulse-wave mode. Key words: chronic obstructive lung disease, ischaemic heart disease, diastolic dysfunction.
\end{abstract}

\section{Резюме}

Целью настоящего исследования была оценка функционально-структурных изменений сердца у пациентов с изолированным течением хронической обструктивной болезни легких (ХОБЛ) в сочетании с ишемической болезнью сердца (ИБС). Использовались методы стандартной и тканевой допплерэхокардиографии. В исследовании участвовали 144 пациента, которые были разделены на 3 группы: 1-я - 59 больных ХОБЛ (I-III стадии), 2-я - 56 пациентов с сочетанием ХОБЛ и ИБС, 3-я (контрольная) - 29 курящих пациентов без клинических и функциональных проявлений сердечно-легочной патологии. Проводились исследование функции внешнего дыхания, эхокардиография у больных всех групп. Сравнивались планиметрические, гемодинамические, параметры тканевой допплерографии. Индекс объема левого предсердия достоверно различался во всех группах: в 1-й - 29,2 $\pm 3,5$; во 2-й - 33,7 $\pm 2,95$; в 3-й $-24,1 \pm 2,3$. Наиболее выраженными различия между группами были при сравнении параметра Е / Еm левого желудочка. В 1-й группе данный показатель возрастал на 49,1 \% по отношению к контрольной группе, а во 2-й - на 132,7 \%. Диастолическая дисфункция левого желудочка (ДДЛЖ) развивалась у $57,6 \%$ пациентов 1-й группы и у 98,2\% - 2-й группы. Систолическое давление в легочной артерии в 1 -й группе было на $15 \%$ выше, а во 2-й - на $55 \%$ выше, чем в группе контроля. Выраженная легочная гипертензия у пациентов 2-й группы приводила к ухудшению работы правого желудочка: индекс миокардиальной производительности правого желудочка почти в 2 раза увеличивался у больных ХОБЛ и еще более - у пациентов с сочетанной патологией. Уменьшение соотношения показателей ранней и поздней диастолической волн при использовании тканевого допплера с латерального кольца трикуспидального клапана регистрировалось у пациентов 1-й группы и было более выраженным во 2-й группе, что подтверждает усиление степени ДДлЖ у пациентов с сочетанием ХОБЛ и ИБС, по сравнению с больными ХОБЛ. Таким образом, метод тканевой допплерографии помогает обнаружить ДД обоих желудочков на более ранней стадии, когда посредством импульсно-волновой допплерографии изменения не выявляются.

Ключевые слова: хроническая обструктивная болезнь легких, ишемическая болезнь сердца, диастолическая дисфункция.

Хроническая обструктивная болезнь легких (ХОБЛ) и ишемическая болезнь сердца (ИБС) нередко сочетаются. На их долю приходится $\sim 62 \%$ в структуре заболеваемости пациентов старших возрастных групп $[1,2]$. В их возникновении особую роль играют общие факторы риска. Так, курение, низкая физическая активность, стрессы, артериальная гипертония, отягощенная ИБС наследственность встречаются более чем у 50 \% больных ХОБЛ.
Длительное течение ХОБЛ приводит к гемодинамическим изменениям со стороны сердечно-сосудистой системы и формированию легочного сердца (ЛС), которое характеризуется гипертрофией, дилатацией, дисфункцией правого желудочка (ПЖ) на фоне легочной гипертензии. Считается, что $50 \%$ больных ХОБЛ старше 50 лет страдают ЛГ и ЛС. По данным аутопсий, у 70 \% пациентов единственной причиной изолированной гипертрофии правого же- 
лудочка (ПЖ), которая служит морфологическим проявлением ЛГ и дисфункции ПЖ, является ХОБЛ.

С развитием ультразвуковой техники появилась возможность более детальной оценки структурнофункциональных изменений со стороны сердца у пациентов с ХОБЛ на различных стадиях заболевания. В литературе достаточно четко описаны критерии диагностики легочного сердца по эхокардиографии. В настоящее время рядом исследователей доказано развитие диастолической дисфункции левого желудочка (ДДЛЖ) уже на ранней стадии ХОБЛ. Нельзя не отметить, что при ХОБЛ не всегда удается достаточно хорошо визуализировать полости сердца из-за сопутствующей эмфиземы, а появление современной ультразвуковой методики тканевого допплера позволяет с высокой степенью достоверности определять основные параметры работы ПЖ [3]. Важным представляется и тот факт, что ХОБЛ часто встречается у пациентов старшей возрастной группы, которые, как правило, имеют уже сопутствующие заболевания, такие как ИБС. Известно, что ИБС приводит к развитию ДДЛЖ. Повышение конечного диастолического давления в ЛЖ способствует присоединению посткапиллярной гипертензии, которая усугубляет дисфункцию правых отделов сердца.

Цель настоящего исследования - оценить функционально-структурные изменения сердца у пациентов с изолированным течением ХОБЛ и в сочетании с ИБС методом стандартной и тканевой допплерэхокардиографии.

\section{Материалы и методы}

Исследование было 1-моментным, поперечным, обсервационным. В нем участвовали 144 пациента, которые находились на стационарном и амбулаторном лечении в ГКБ № 57. Все они были разделены на 3 группы. В 1-ю группу были включены пациенты ХОБЛ легкой, средней и тяжелой степени - 59 человек (49 мужчин и 10 женщин). Их средний возраст составлял 63,1 \pm 5,9 года. Диагноз ХОБЛ подтверждался данными анамнеза, клинической картины, функциональных и рентгенологических методов диагностики в соответствии с критериями GOLD пересмотра 2008 г. Основной критерий включения пациентов наличие обструкции дыхательных путей, которая определялась методом спирометрии по показателям объема форсированного выдоха за 1-ю с $\left(\mathrm{OФB}_{1}\right)$ и отношения ОФВ 1 к форсированной жизненной емкости легких (ОФВ 1 / ФЖЕЛ). Во 2-ю группу вошли пациенты с ХОБЛ легкой, средней и тяжелой степени в сочетании с ИБС - 56 человек, из них 47 мужчин $(83,9 \%)$ и 9 женщин $(16,1 \%)$. Средний возраст $62,9 \pm 6,4$ года. ХОБЛ диагностировали так же, как и в 1-й группе. Во 2-ю группу включались больные ИБС с постинфарктным кардиосклерозом в анамнезе и нормальной систолической функцией ЛЖ.

Пациентам обоих групп было проведено суточное мониторирование артериального давления (АД), чтобы исключить тяжелую форму артериальной гипертензии (по классификации ВОЗ 1999 г.). На момент исследования ни у одного пациента не было обострения. Больные обеих групп получали стандартную терапию (бронхолитики, муколитики, антиагреганты, нитраты), однако за 24 ч до исследования отменялись все препараты, чтобы избежать их влияния на сердечную гемодинамику. В 3-ю группу, контрольную, вошли 29 человек, из них 24 мужчины (82,8 \%) и 5 женщин $(17,2 \%)$ с длительным стажем курения > 10 пачек / лет. Средний возраст $-63,0+5,4$ года. У этих пациентов не было выявлено легочных или сердечно-сосудистых заболеваний, что подтверждалось клиническими и инструментальными исследованиями органов дыхания и сердечно-сосудистой системы. Критериями включения были показатели спирометрии в пределах возрастной нормы $\left(\mathrm{OФВ}_{1}>80 \%\right.$, ОФВ $_{1} /$ ФЖЕЛ $>70 \%)$, отсутствие патологических изменений электрокардиограммы (ЭКГ) в покое и при проведении велоэргометрического нагрузочного теста.

Исследование функции внешнего дыхания (ФВД) проводилось с использованием аппаратуры MasterScreen (Erich Jaeger, Германия). Ультразвуковое исследование сердца выполнялось на аппарате VIVID-7 (General Electric, США) с использованием датчика 3,5 мГц. Эхокардиографическая запись была синхронизирована с ЭКГ.

Измерялись левые отделы сердца в парастернальной позиции в режимах В и М. Определялись следующие параметры ЛЖ: конечно-диастолический (КДРЛЖ) и конечно-систолический размеры (КСРЛЖ), толщина межжелудочковой перегородки (МЖП) в диастоле, толщина задней стенки левого желудочка (ЗСЛЖ) в диастоле, фракция выброса левого желудочка (ФВЛЖ, \%) по Тейхольцу, фракция укорочения левого желудочка (ФУЛЖ, \%). В апикальной позиции в В-режиме выявлялись линейные размеры ЛЖ и левого предсердия (ЛП). Индекс объема ЛП (ИОЛП) рассчитывали по формуле:

\section{иОлП = ОЛП : ППТ,}

где ОЛП - объем ЛП, ППТ - площадь поверхности тела.

Диастолическую функцию ЛЖ (ДФЛЖ) оценивали с использованием импульсно-волнового допплера:

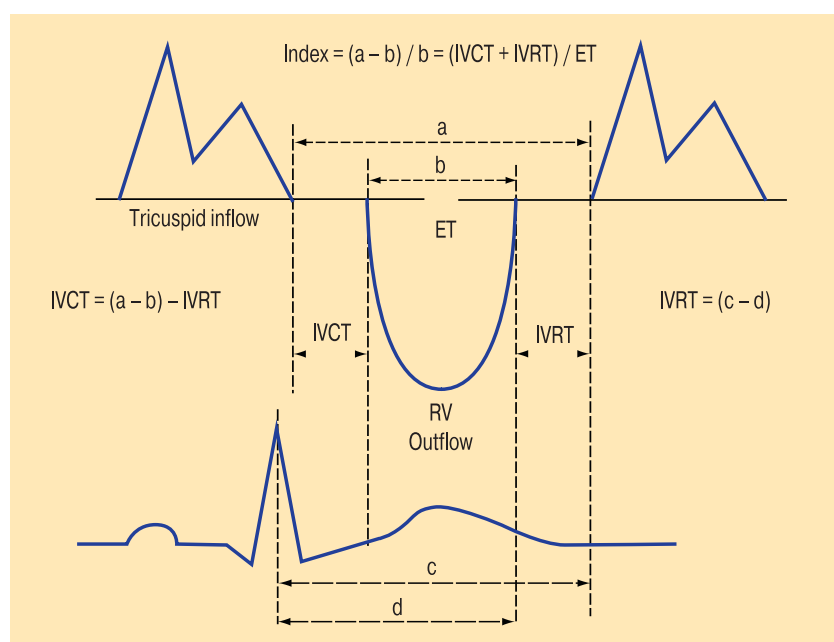

Рис. 1. Расчет индекса MPI [4] 
измеряли пик Е и пик А над створками митрального клапана, время замедления пика Е (DT пика E), рассчитывали отношение E / А. Для более точной оценки диастолической и систолической функций ЛЖ на уровне митрального фиброзного кольца использовали метод тканевого допплера. Измеряли пик $\mathrm{S}$, пик Am и пик Em, отношение Em / Am, время изоволюметрического сокращения ЛЖ (IVCT), время изоволюметрического расслабления ЛЖ (IVRT), время выброса (ЕT). Затем рассчитывали индекс миокардиальной производительности (МРI) (рис. 1):

\section{MPI LV = IVRT + IVCT : ET}

Давление заклинивания в легочной артерии (ДЗЛА) определяли по формуле:

$$
\text { ДЗЛА }=1,3 \times E: E m+1,2
$$

Для правых отделов измерялись следующие показатели: толщина стенки ПЖ, линейный размер ПЖ и ПП, систолическое давление в легочной артерии (СДЛА, мм рт. ст.), среднее давление в легочной артерии (СрДЛА, мм рт. ст.). Диастолическую функцию ПЖ (ДФПЖ) оценивали с использованием импульсно-волнового допплера: измеряли пик Е и пик А над створками 3-створчатого клапана, DT пика E,

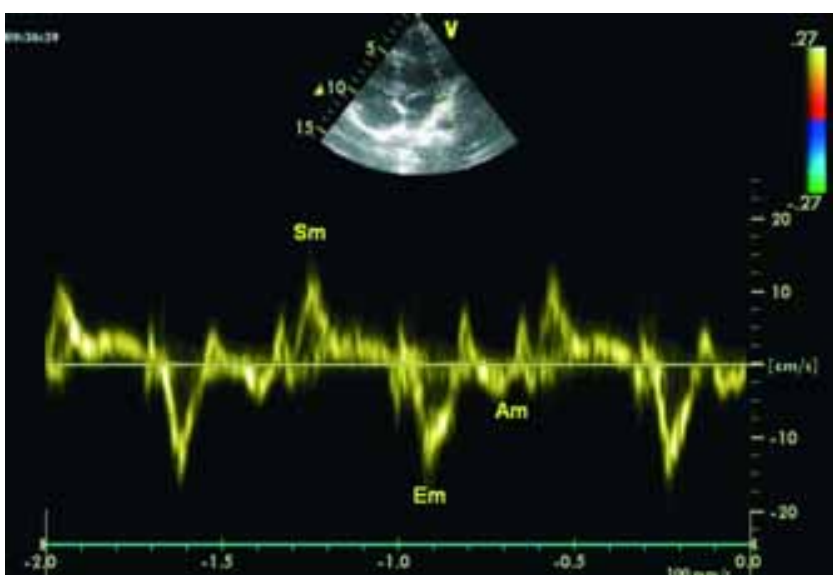

Рис. 2. Тканевой допплер (латеральное кольцо митрального клапана) рассчитывали Е / А. Для более точной оценки диастолической и систолической функций ПЖ на уровне 3-створчатого фиброзного кольца использовали метод тканевого допплера (рис. 2). Измеряли пик S, пик Am и пик Em, отношение Em / Am, время изоволюметрического сокрашения ПЖ (IVCT), время изоволюметрического расслабления ПЖ (IVRT), время выброса (ЕT). Кроме того, рассчитывался MPI по формуле:

\section{$M P I R V=I V R T+I V C T / E T$}

Статистическую обработку полученных данных осуществляли с помощью методов вариационной статистики, применяя программу Statictica 6.0. Статистическую значимость различия средних определяли посредством критерия Стьюдента при уровне значимости $p<0,05$.

\section{Результаты}

В табл. 1 приведена сравнительная характеристика пациентов. Все они не отличаются по полу, возрасту, частоте сердечных сокращений (ЧСС). Различия в АД между группами закономерны; уровень АД в 1-й и 2-й группах был незначительно выше, чем в группе контроля. Стаж курения значительно больше (в 3,5 раза) у больных 1-й и 2-й групп, по сравнению с 3-й. Спирометрические параметры в контрольной группе находились в пределах нормальных величин. Показатели ЖЕЛ были ниже в 1-й и 2-й группах, по сравнению с контрольной, на 6,9 \% и 14,2 \% соответственно. Показатели ОФВ 1 снижены в 1-й и 2-й

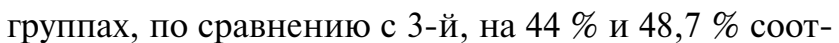
ветственно. Индекс Тиффно в 1-й группе меньше на 46,2 \%, а во 2-й - на 44,4\%, по сравнению с 3-й.

\section{Исследование функции левых отделов}

В ходе межгруппового анализа параметров (табл. 2) было выявлено, что ИОЛП достоверно ( $p<0,001)$ различался во всех 3 группах, увеличиваясь от группы контроля $(24,1 \pm 2,3)$ к 1-й $(29,2 \pm 3,5$; прирост $21,2 \%)$ и 2-й группе $(33,7 \pm 2,95$; прирост $-39,8 \%)$.

Таблица 1

Сравнительная характеристика пациентов

\begin{tabular}{|c|c|c|c|c|}
\hline Характеристика & Контроль, 3-я группа ( $=29$ ) & 1 -я группа $(n=59)$ & 2-я группа ( $n=56)$ & Достоверность различий \\
\hline Мужчины, $n$ (\%) & $24(82,8)$ & $49(83,1)$ & $47(83,9)$ & НД \\
\hline Женщины, $n$ (\%) & $5(17,2)$ & $10(16,9)$ & $9(16,1)$ & НД \\
\hline Возраст, лет & $63,0 \pm 5,4$ & $63,1 \pm 5,9$ & $62,9 \pm 6,4$ & НД \\
\hline Стаж курения, пачек / лет & $10,6 \pm 7,6$ & $35,5 \pm 10,2$ & $35,4 \pm 12,8$ & $p_{1}<0,001 ; p_{2}<0,001 ; p_{3}-$ НД \\
\hline ХОБЛ: легкая степень, $n$ (\%) & 0 & $2(3,4)$ & $1(18)$ & $p_{1}<0,001 ; p_{2}<0,001 ; p_{3}-$ НД \\
\hline ХОБЛ: средняя степень, $n$ (\%) & 0 & $28(47,5)$ & $21(37,5)$ & $p_{1}<0,001 ; p_{2}<0,001 ; p_{3}-$ НД \\
\hline ХоБЛ: тяжелая степень, n (\%) & 0 & $29(49,1)$ & $34(60,7)$ & $p_{1}<0,001 ; p_{2}<0,001 ; p_{3}-$ НД \\
\hline ЧСС, мин $^{-1}$ & $70,4 \pm 6,3$ & $67,00 \pm 7,75$ & $68,1 \pm 10,1$ & нд \\
\hline Систолическое АД, мм рт. ст. & $126,4 \pm 10,3$ & $131,0 \pm 5,5$ & $138,9 \pm 10,5$ & $p_{1}<0,01 ; p_{2}<0,001 ; p_{3}<0,001$ \\
\hline Диастолическое АД, мм рт. ст. & $74,3 \pm 9,1$ & $76,8 \pm 6,1$ & $82,6 \pm 10$ & $p_{1}-$ НД; $p_{2}<0,001 ; p_{3}<0,001$ \\
\hline ЖЕЛ, \% & $101,0 \pm 10,2$ & $94,0 \pm 15,2$ & $86,7 \pm 10,7$ & $p_{1}<0,05 ; p_{2}<0,001 ; p_{3}<0,01$ \\
\hline $\mathbf{0} \mathbf{\Phi B}_{1}, \%$ & $93,5 \pm 10,2$ & $52,1 \pm 12,6$ & $48,0 \pm 12,6$ & $p_{1}<0,001 ; p_{2}<0,001 ; p_{3}-$ НД \\
\hline ОФВ 1 / ФЖЕЛ, \% & $80,1 \pm 7,1$ & $43,1 \pm 10,9$ & $44,5 \pm 11,1$ & $p_{1}<0,001 ; p_{2}<0,001 ; p_{3}-$ НД \\
\hline
\end{tabular}

Примечание: $p_{1}$ - различия между 1-й и 3-й группами; $p_{2}$ - 2-й и 3-й группами; $p_{3}$ - 1-й и 2-й группами; НД - различия не достоверны. 
Наиболее выраженными различия между группами были при сравнении параметра Е / Еm ЛЖ. В группе ХОБЛ данный показатель был выше на 49,1 \%, по сравнению с контрольной, в группе с сочетанной патологией - на 132,7 \%. Диастолические пики тканевого допплера с латеральной части митрального клапана, за исключением пика Аm, отличаются между группами с высокой степенью достоверности ( $p<$ 0,01). По сравнению с контролем, пик Еm ЛЖ ниже в 1-й и 2-й группах - на 31,5\% и 48,5\% соответственно. Соотношение диастолических пиков тканевого допплера Em / Am уменьшается в группе ХОБЛ и еще больше - в группе с сочетанием ХОБЛ и ИБС (на $17 \%$ и 41,5\% соответственно). МРІ ЛЖ достоверно повышался в 1-й и 2-й группах на 15,1\% и $30,2 \%$ соответственно.

\section{Исследование функции правых отделов}

Размер ПЖ в 3 группах не различался. Размер ПП был увеличен у пациентов с ХОБЛ и с сочетанием ХОБЛ и ИБС. Самая большая толщина МЖП была зарегистрирована во 2-й группе, что, вероятно, связано с большим количеством случаев артериальной гипертензии у таких больных. Толщина свободной стенки ПЖ была значительно увеличена в 1-й и 2-й группах, но различий между ними не выявлено. СДЛА у пациентов с ХОБЛ было на 15,7 \% выше, чем в группе контроля $(p<0,05)$, а в группе с сочетанной патологией - на $55 \%$ выше $(p<0,001)$. Различия СрДЛА более достоверны: во 2-й группе - на $116,9 \%$, в 1-й - на 42,2 \% выше, чем в 3-й группе.

Различия показателей диастолических пиков, полученных посредством традиционного импульсно-волнового допплера и тканевого допплера, были менее выраженными. Отношение диастолических пиков ПЖ Е / А выше в группе контроля на 15,5 \%, по сравнению с 1-й группой $(p<0,001)$, и на $24 \%$ больше, чем во 2-й группе $(p<0,001)$. Соотношение Em / Am ПЖ ниже в 1-й группе на 40,4 \%, а во 2-й на 48,9 \%, чем в группе контроля. Наиболее важным интегральным показателем функции ПЖ является его MPI, который в 3-й группе составил 0,37 \pm 0,03, что незначительно превышает нормальное значение. В 1-й группе он был выше на 70,3 \%, а во 2-й - на $110,8 \%$.

\section{Обсуждение}

Сравниваемые группы не отличались по полу, возрасту, но стаж курения и проявления артериальной гипертензии были разными. Дополнительный стратификационный анализ по стадиям ХОБЛ не проводился. Не было получено зависимости между параметрами ФВД $\left(\mathrm{OФВ}_{1}\right.$ и ЖЕЛ) и эхокардиографическими данными, что не противоречит данным других исследователей [5]. Линейные размеры правого желудочка не отличаются между группами. Однако есть различия между группами в размерах правого предсердия, что связано с увеличением СДЛА и СрДЛА во 2-й и 3-й группах. Данные изменения могут быть обусловлены присоединением посткаппилярной (венозной) гипертензии у пациентов с сочетанной патологией, что приводит к более значимому повышению давления в легочной артерии.

О развитии посткапиллярной гипертензии у таких больных может свидетельствовать и увеличение ИОЛП во 2-й группе. Обращают на себя внимание и более выраженные изменения в ПЖ у пациентов с сочетанной патологией, например гипертрофия свободной стенки ПЖ и МЖП. Достаточно информативным показателем оценки систоло-диастолической функции ПЖ является его MPI, который

Таблица 2

Межсрупповой сравнительный анализ параметров левых отделов сердца

\begin{tabular}{|c|c|c|c|c|}
\hline Характеристика & Контроль, 3-я группа ( $n=29)$ & 1-я группа (n= 59) & 2-я группа $(n=56)$ & Достоверность различий \\
\hline КДР, мм & $43,7 \pm 3,1$ & $41,4 \pm 4,7$ & $43,4 \pm 5,8$ & нд \\
\hline КСР, мм & $27,5 \pm 2,9$ & $27,4 \pm 4,5$ & $28,8 \pm 7,5$ & нд \\
\hline$\Phi \mathbf{B}, \%$ & $66,7 \pm 4,6$ & $65,7 \pm 6,2$ & $66,4 \pm 7,8$ & нд \\
\hline ЛЖ, мм & $39,4 \pm 2,0$ & $40,8 \pm 4,4$ & $41,6 \pm 5,6$ & нд \\
\hline$Л \Pi_{1}, \mathrm{Mм}$ & $40,3 \pm 3,2$ & $42,2 \pm 5,0$ & $46,6 \pm 6,7$ & $p_{1}-$ НД; $p_{2}<0,001 ; p_{3}<0,001$ \\
\hline лП 2, мм & $34,4 \pm 4,3$ & $36,3 \pm 5,9$ & $38,9 \pm 8,8$ & $p_{1}-$ НД; $p_{2}<0,05 ; p_{3}-$ НД \\
\hline иолп, мл/м² & $24,1 \pm 2,3$ & $29,2 \pm 3,5$ & $33,70 \pm 2,95$ & $p_{1}<0,001 ; p_{2}<0,001 ; p_{3}<0,001$ \\
\hline Е ЛЖ, см/с & $68,7 \pm 7,0$ & $66,7 \pm 11,9$ & $75,5 \pm 18,7$ & $p_{1}-$ НД; $p_{2}-$ НД; $p_{3}<0,01$ \\
\hline А ЛЖ, см/с & $61,9 \pm 6,4$ & $75,9 \pm 12,4$ & $73,3 \pm 14,4$ & $p_{1}<0,001 ; p_{2}<0,001 ; p_{3}-$ НД \\
\hline Е / А ЛЖ & $1,110 \pm 0,062$ & $0,910 \pm 0,204$ & $1,090 \pm 0,417$ & $p_{1}<0,001 ; p_{2}-$ НД; $p_{3}<0,01$ \\
\hline Е / Еm ЛЖ & $5,50 \pm 0,96$ & $8,20 \pm 2,50$ & $12,80 \pm 5,65$ & $p_{1}<0,001 ; p_{2}<0,001 ; p_{3}<0,001$ \\
\hline Еm ЛЖ, см/с & $12,40 \pm 1,40$ & $8,50 \pm 2,18$ & $6,40 \pm 1,43$ & $p_{1}<0,001 ; p_{2}<0,001 ; p_{3}<0,001$ \\
\hline Аm ЛЖ, см/с & $11,80 \pm 1,26$ & $10,20 \pm 2,41$ & $10,50 \pm 2,40$ & $p_{1}<0,001 ; p_{2}<0,01 ; p_{3}-$ НД \\
\hline $\mathrm{Em} / \mathrm{Am}$ & $1,060 \pm 0,090$ & $0,880 \pm 0,214$ & $0,620 \pm 0,141$ & $p_{1}<0,01 ; p_{2}<0,001 ; p_{3}<0,001$ \\
\hline DT пика E, мс & $184,4 \pm 12,0$ & $217,5 \pm 34,3$ & $197,5 \pm 57,9$ & $p_{1}<0,01 ; p_{2}-$ НД; $p_{3}<0,05$ \\
\hline IVCT лЖ, мс & $75,3 \pm 6,7$ & $75,7 \pm 14,4$ & $80,3 \pm 22,0$ & нд \\
\hline IVRT ЛЖ, мс & $78,7 \pm 6,5$ & $94,7 \pm 18,6$ & $88,2 \pm 31,5$ & $p_{1}<0,001 ; p_{2}-$ НД; $p_{3}-$ НД \\
\hline ЕТ лЖ, мс & $294,1 \pm 10,0$ & $282,2 \pm 24,7$ & $245,8 \pm 33,5$ & $p_{1}<0,05 ; p_{2}<0,001 ; p_{3}<0,001$ \\
\hline МРІ ЛЖ & $0,530 \pm 0,041$ & $0,610 \pm 0,134$ & $0,690 \pm 0,187$ & $p_{1}<0,01 ; p_{2}<0,001 ; p_{3}<0,01$ \\
\hline
\end{tabular}

Примечание: $p_{1}$ - различия между 1-й и 3-й группами; $p_{2}$ - 2-й и 3-й группами; $p_{3}$ - 1-й и 2-й группами; НД - различия не достоверны. 
Таблица 3

Межсрупповой сравнительный анализ параметров правых отделов сердца

\begin{tabular}{|c|c|c|c|c|}
\hline Параметр & 1 -я группа ( $n=59)$ & 2-я группа (n = 56) & Контроль, 3-я группа ( = 29) & Достоверность различий \\
\hline ПЖ, мм & $29,8 \pm 3,1$ & $31,0 \pm 4,5$ & $29,6 \pm 2,7$ & нд \\
\hline$\Pi \Pi_{1}$, мм & $43,3 \pm 3,1$ & $43,8 \pm 7,2$ & $39,2 \pm 5,0$ & $p_{1}<0,001 ; p_{2}<0,01 ; p_{3}-$ НД \\
\hline$\Pi \Pi_{2}, \mathrm{Mм}$ & $35,5 \pm 4,5$ & $39,7 \pm 7,6$ & $33,2 \pm 3,9$ & $p_{1}<0,05 ; p_{2}<0,001 ; p_{3}<0,001$ \\
\hline МЖП, мм & $12,4 \pm 1,4$ & $13,3 \pm 2,1$ & $9,9 \pm 1,7$ & $p_{1}<0,001 ; p_{2}<0,001 ; p_{3}<0,01$ \\
\hline Толщина ПЖ, мм & $7,6 \pm 7,7$ & $8,00 \pm 1,61$ & $5,60 \pm 0,56$ & $p_{1}<0,001 ; p_{2}<0,001 ; p_{3}-$ НД \\
\hline СДЛА, мм рт. ст. & $22,1 \pm 6,3$ & $29,60 \pm 10,83$ & $19,10 \pm 1,35$ & $p_{1}<0,05 ; p_{2}<0,001 ; p_{3}<0,001$ \\
\hline СрДЛА, мм рт. ст. & $11,8 \pm 5,1$ & $18,00 \pm 9,01$ & $8,30 \pm 0,72$ & $p_{1}<0,001 ; p_{2}<0,001 ; p_{3}<0,001$ \\
\hline Е ПЖ, см/с & $53,5 \pm 9,1$ & $49,6 \pm 8,8$ & $49,1 \pm 4,1$ & $p_{1}<0,05 ; p_{2}-$ НД; $p_{3}<0,05$ \\
\hline А ПЖ см/с & $49,9 \pm 7,4$ & $50,9 \pm 5,9$ & $38,00 \pm 4,06$ & $p_{1}<0,001, p_{2}<0,001, p_{3}-$ НД \\
\hline E / A ПЖ & $1,09 \pm 0,16$ & $0,980 \pm 0,173$ & $1,290 \pm 0,075$ & $p_{1}<0,001 ; p_{2}<0,001 ; p_{3}<0,01$ \\
\hline DT пика E, мс & $164,6 \pm 25,3$ & $192,6 \pm 45,5$ & $187,3 \pm 7,4$ & $p_{1}<0,001 ; p_{2}-$ НД; $p_{3}<0,001$ \\
\hline Em ПЖ & $14,70 \pm 2,17$ & $15,20 \pm 2,32$ & $16,20 \pm 1,34$ & $p_{1}<0,01 ; p_{2}<0,05 ; p_{3}-$ НД \\
\hline Am ПЖ & $17,90 \pm 3,98$ & $21,80 \pm 4,75$ & $11,60 \pm 1,24$ & $p_{1}<0,001, p_{2}<0,001, p_{3}<0,001$ \\
\hline Em / Am ПЖ & $0,840 \pm 0,125$ & $0,720 \pm 0,136$ & $1,410 \pm 0,110$ & $p_{1}<0,001 ; p_{2}<0,001 ; p_{3}<0,001$ \\
\hline IVCT пж & $73,5 \pm 6,3$ & $76,70 \pm 6,15$ & $52,9 \pm 4,1$ & $p_{1}<0,001 ; p_{2}<0,001 ; p_{3}<0,01$ \\
\hline IVRT ПЖ & $78,4 \pm 17,0$ & $98,6 \pm 26,4$ & $57,7 \pm 4,1$ & $p_{1}<0,001 ; p_{2}<0,001 ; p_{3}<0,001$ \\
\hline ЕТ пЖ & $243,0 \pm 20,7$ & $228,8 \pm 18,8$ & $290,8 \pm 9,8$ & $p_{1}<0,001 ; p_{2}<0,001 ; p_{3}<0,001$ \\
\hline MPI ПЖ & $0,630 \pm 0,139$ & $0,780 \pm 0,189$ & $0,370 \pm 0,030$ & $p_{1}<0,001 ; p_{2}<0,001 ; p_{3}<0,001$ \\
\hline
\end{tabular}

Примечание: $p_{1}$ - различия между 1-й и 3-й группами; $p_{2}$ - 2-й и 3-й группами; $p_{3}$ - 1-й и 2-й группами; НД - различия не достоверны.

почти в 2 раза увеличивался в 1-й группе и еще более - во 2-й.

Использование тканевого допплера позволяет более точно охарактеризовать дисфункцию ПЖ в исследуемых группах. Так, в отличие от отношения диастолических пиков импульсно-волнового допплера (Е / А ПЖ), которое показало дисфункцию только во 2-й группе, изменение отношение Em / Аm тканевого допплера отмечалось уже в 1-й группе, что свидетельствует о его большей чувствительности в диагностике ДДПЖ (рис. 3).

Данные о вовлечении ЛЖ в патологический процесс у пациентов с ХОБЛ достаточно противоречивы. Присоединение к ХОБЛ ИБС значительно усугубляет изменения в ЛЖ. Сложной представляется диагностика этих изменений, до снижения систолической функции ЛЖ. Известно, что структурные изменения ЛЖ при ИБС могут быть связаны с нако-

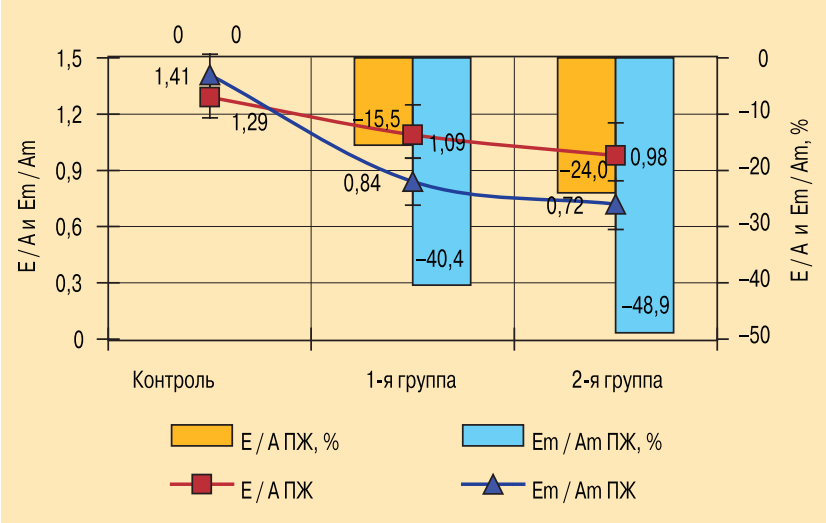

Рис. 3. Сравнительный анализ изменений Е / А и Em / Am ПЖ: комбинированная диаграмма абсолютных (точечные маркеры) значений параметров Е / А и Em / Am и процентных изменений между группами (столбовая диаграмма) по отношению к контрольной группе плением коллагена II типа в межклеточном пространстве, что приводит к повышению диастолической жесткости стенок ЛЖ [6]. Методика импульсноволнового допплера недостаточно чувствительна для оценки диастолической дисфункции ЛЖ, что затрудняет интерпретацию данных. При анализе скоростных параметров импульсно-волнового допплера в 1-й и 2-й группах были получены противоречивые данные (рис. 4). Отношение Е / А в группе контроля составляло $1,110 \pm 0,062$, а во 2-й группе $-1,09 \pm$ 0,417 , т. е. достоверные отличия отсутствовали. Однако известно, что диастолической дисфункции ухудшается уже с I стадии ДД (нарушение ДДЛЖ по 1 типу). Хотя II стадия ДД (псевдонормальная) характеризуется тем, что скоростные параметры импульсно-волнового допплера соответствуют норме, она является переходной от I стадии ДД к более тяжелой III стадии - рестриктивной. Представляется,

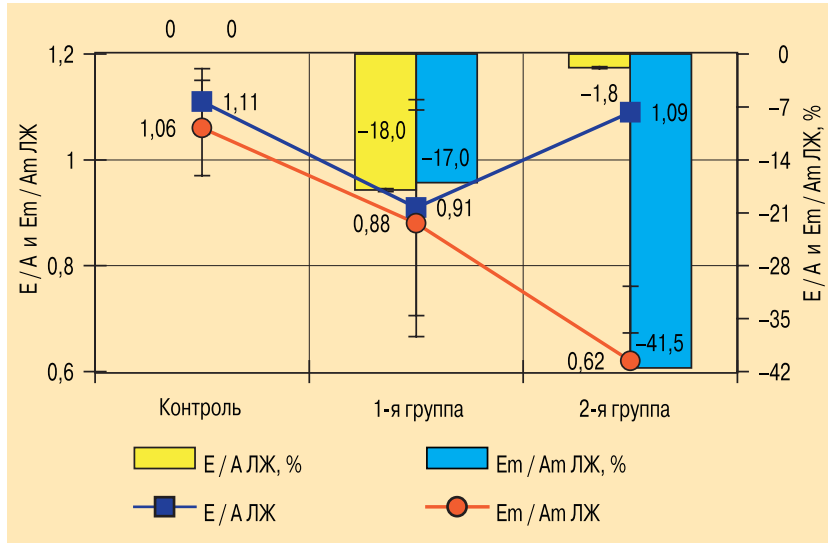

Рис. 4. Сравнительный анализ изменений Е / А и Еm / Am ЛЖ: комбинированная диаграмма абсолютных (точечные маркеры) значений параметров E / А и Em / Аm и процентных изменений между группами (столбовая диаграмма) по отношению к контрольной группе 
что такие показатели по группам были получены в значительной степени именно из-за "псевдонормализации" скоростных параметров импульсно-волнового допплера на II стадии ДД у пациентов с ХОБЛ и ИБС. Параметры тканевого допплера изменяются более закономерно: диастолический пик Еm наиболее высок в группе контроля, ниже - у больных ХОБЛ и минимальный - при сочетанной патологии. Это оказывает влияние на отношение Em / Am, которое изменяется следующим образом: максимальное среднее значение - в группе контроля (1,06 \pm $0,09)$, что подтверждает отсутствие диастолической дисфункции. Во 1-й и 2-й группах этот показатель был ниже: $0,880 \pm 0,214$ и 0,620 $\pm 0,141$ соответственно, что свидетельствует о функциональных проявлениях ДДЛЖ. Кроме того, показатель соотношения первых пиков импульсного и тканевого допплера Е / Em ЛЖ от группы к группе изменяется линейно, что подтверждает усиление степени ДДЛЖ у больных ХОБЛ и ХОБЛ в сочетании с ИБС, по сравнению с группой контроля.

\section{Заключение}

1. ДДЛЖ развивалась у 57,6 \% больных ХОБЛ и у 98,2 \% пациентов с сочетанием ХОБЛ и ИБС.

2. При сочетании ХОБЛ и ИБС выявлено более значимое увеличение СДЛА, в сравнении с пациентами в группе ХОБЛ.

3. Выраженная легочная гипертензия приводит к ухудшению работы ПЖ, а именно усилению ДДПЖ в группе с сочетанной патологией, по сравнению с больными ХОБЛ, что проявляется увеличением MPI ПЖ, а также достоверными изменениями соотношений Em / Am, E / Em и IVRT ПЖ.

4. Применение технологии тканевого допплера позволяет на ранней стадии и с большей достоверностью выявить ДДЛЖ, используя соотношение показателей тканевой допплерографии с латерального кольца митрального клапана Em / Am и выявить диастолическую дисфункцию ПЖ, ис- пользуя соотношение показателей тканевой допплерографии с латерального кольца трикуспидального клапана Em / Am.

\section{Литература}

1. Козлова Л.И. Хронические обструктивные заболевания легких и ишемическая болезнь сердца: некоторые аспекты функциональной диагностики. Пульмонология 2001; 2: 9-12.

2. Paulus W.J., Tschope C., Sanderson J.E. et al. How to diagnose diastolic heart failure: a consensus statement on the diagnosis of heart failure with normal left ventricular ejection fraction by the Heart Failure and Echocardiography Associations of the European Society of Cardiol. Eur. Heart J. 2007; 28 (20): 2539-2550.

3. Caso P., Galderisi M., Cicala S. et al. Cioppa association between myocardial right ventricular relaxation time and pulmonary arterial pressure in chronic obstructive lung disease: analysis by pulsed Doppler tissue imaging. J. Am. Soc. Echocardiogr. 2001; 14 (10): 970-977.

4. Tei $C$. New non-invasive index for combined systolic and diastolic ventricular function. J. Cardiol. 1995; 26 (2): 135-136.

5. Yilmaz R., Gencer M., Ceylan E., Demirbag R. Impact of chronic obstructive pulmonary disease with pulmonary hypertension on both left ventricular systolic and diastolic performance. J. Am. Soc. Echocardiogr. 2005; 18 (8): 873-881.

6. Spinale F.G., Coker M.L., Bond B.R., Zellner J.L. Myocardial matrix degradation and metalloproteinase activation in the failing heart: a potential therapeutic target. Cardiovasc. Res. 2000; 46 (2): 225-238.

\section{Информация об авторах}

Горелик Ирина Львовна - врач отделения функциональной диагностики ГКБ № 57; тел.: (495) 465-53-37

Калманова Елена Николаевна - к. м. н., зав. отделением функциональной диагностики ГКБ № 57; тел.: (495) 465-53-37; e-mail: kalmanova @mail.ru

Айсанов Заурбек Рамазанович - д. м. н., проф., зав. отделом клинической физиологии и клинических исследований ФГУ "НИИ пульмонологии ФМБА России"; тел.: (495) 465-53-84; e-mail: aisanov@mail.ru Чучалин Александр Григорьевич - акад. РАМН, д. М. Н., проф., директор ФГУ "НИИ пульмонологии ФМБА России"; тел.: (495) 465-52-64 